Article

\title{
Aromatic Polyesters Containing Ether and a Kinked Aromatic Amide Structure in the Main Chain: Synthesis and Characterisation
}

Satish S. Deokar ${ }^{1, *}$, Makarand D. Joshi ${ }^{2}$, Asiya M. Tamboli ${ }^{3, *}$, Sultan Alshehri ${ }^{4}{ }^{(D}$, Mohammed M. Ghoneim ${ }^{5}(\mathbb{D}$, Nguyen Tam Nguyen Truong ${ }^{3, *}$, Mohaseen S. Tamboli ${ }^{6, *}$ and Noormahamad N. Maldar ${ }^{7}$

check for

updates

Citation: Deokar, S.S.; Joshi, M.D.;

Tamboli, A.M.; Alshehri, S.; Ghoneim, M.M.; Truong, N.T.N.; Tamboli, M.S.; Maldar, N.N. Aromatic Polyesters Containing Ether and a Kinked Aromatic Amide Structure in the Main Chain: Synthesis and Characterisation. Coatings 2022, 12, 181. https:// doi.org/10.3390/coatings12020181

Academic Editor: Nadia Lotti

Received: 30 December 2021

Accepted: 27 January 2022

Published: 30 January 2022

Publisher's Note: MDPI stays neutral with regard to jurisdictional claims in published maps and institutional affiliations.

Copyright: (c) 2022 by the authors. Licensee MDPI, Basel, Switzerland. This article is an open access article distributed under the terms and conditions of the Creative Commons Attribution (CC BY) license (https:// creativecommons.org/licenses/by/ $4.0 /)$.
Department of Chemistry, Shankarrao Mohite Mahavidyalaya, Akluj 413101, India

Guru Nanak Dev Institute of Technology, Rohini, New Delhi 110089, India; makarandjoshi@yahoo.co.in School of Chemical Engineering, Yeungnam University, 280 Daehak-ro, Gyeongsan 38541, Korea

4 Department of Pharmaceutics, College of Pharmacy, King Saud University, Riyadh 11451, Saudi Arabia; salshehri1@ksu.edu.sa

5 Department of Pharmacy Practice, College of Pharmacy, Almaarefa University, AdDiriyah 13713, Saudi Arabia; mghoneim@mcst.edu.sa

6 Korea Institute of Energy Technology (KENTECH), 200 Hyeokshin-ro, Naju 58330, Jeollanam-do, Korea

7 School of Chemical Sciences, P. A. H. Solapur University, Solapur 413255, India; maldar.nn@gmail.com

* Correspondence: ssdeokarchem@gmail.com (S.S.D.); asiyashaikh2020@gmail.com (A.M.T.); tamnguyentn@ynu.ac.kr (N.T.N.T.); tamboli.mohseen@gmail.com (M.S.T.)

\begin{abstract}
A novel bisphenol containing preformed multiple ether and amide linkages, N, N'-Bis (4-hydroxyphenoxyphenylene) isophthalamide (IPCD), was prepared and analysed by spectroscopic methods. New aromatic polyesters were prepared by polycondensation of IPCD with 1, 3-benzene diacidchloride and/or 1, 4-benzene diacidchloride. These obtained polyesters were structurally analysed by infra-red spectroscopy, measurements of inherent viscosity, wide-angle X-ray diffraction patterns, and thermal techniques such as differential scanning calorimetry (DSC), thermogravimetric analysis (TGA), and solubility tests in organic solvents. The synthesised polyesters had high molecular weights, as indicated by their inherent viscosities from 0.67 to $0.78 \mathrm{dL} / \mathrm{g}$ in N-methyl-2-pyrrolidone. The incorporation of ether and kinked aromatic amide moieties in the main polyester chains greatly affected the properties of these aromatic polyesters. The prepared polyesters readily dissolved in amide-type polar aprotic solvents and pyridine, indicating their solution processability. The DSC curves above the polyesters showed glass transition temperatures of 194 to $269^{\circ} \mathrm{C}$. TGA indicated that these newly obtained polyesters were stable up to $301{ }^{\circ} \mathrm{C}$ and retained a 39 to $48 \%$ weight at $900{ }^{\circ} \mathrm{C}$. W-XRD analyses showed that the newly synthesised polyesters were amorphous, which is reflected in their solubility behaviour.
\end{abstract}

Keywords: N, N'-Bis (4-hydroxyphenoxyphenylene) isophthalamide; soluble aromatic polyesters; glass transition temperatures; high-temperature stability; XRD

\section{Introduction}

Aromatic polyesters have good thermal stability and other physico-mechanical properties, leading to their wide applications in various important state-of-the-art industries [1-3]. However, wholly polyarylates are insoluble and have high glass transition or melting temperatures and are hence difficult to process. The ordering and structural variations of polymer backbones decide the final properties of the polymer [4,5]. Earlier investigations showed that modified cardo groups [6,7] and pendant moieties [8-12] produced amorphous polyesters that dissolved in organic solvents. Polyesters derived from CNSLbased monomers showed relatively lower glass transition temperatures in addition to the enhanced solubility of these polyesters in some organic solvents, probably due to the plasticising effect of the pendant long pentadecyl alkyl groups [5,9]. Good melt-processability 
of the polymers required lower glass transition temperatures so that processing could be performed at relatively lower temperatures. However, the same pentadecyl alkyl groups decreased the thermal stability of the resulting polyesters. [11] Pendant biphenyl [3], naphthyl [10], or phenothiazine moiety [12] in aromatic polyesters improved the solubility of resulting polyesters, and there was no significant loss in their thermal stability. Linkages such as ether and sulphone in polymers increased the solubility and solution processability without any comprise in the polymer thermal stability [13-16].

Aromatic polymers containing the ether and amide side groups showed improved solubility and thermal stability [17]. To achieve these properties in high-performance polymers, various flexible ether linkages were incorporates to yield poly(ether ester)s and poly(ether amide)s [18,19]. High-molecular-weight terephthalate copolyesters from flexible cycloaliphatic diols or diacids displayed a coherent structure-property relationship related to the rigid, flexible, and bulky structures [20,21]. The copolyesterification process also enhanced the solubility of resulting polyesters due to a formation of the random, irregular arrangement in polymer chains. Thus, ether moieties in aromatic polymers and random copolymerisation increased the flexibility of these polymers. Enhanced flexibility decreased glass transition temperatures and enhanced polymer solubility. Thus it assisted in overcoming the difficulty of polymer processing [22-24].

Based on these concepts, it was thought to synthesise bisphenol-containing, preformed ether and amide groups, wherein kink or m-catenation links could be provided at few aromatic units as it would be more effective for improving the solubility of the resulting poly(ether ester)s. Thus, this report includes the synthesis and characterisation of a new, modified bisphenol, namely N, $\mathrm{N}^{\prime}$-[ $4^{\prime}-\left(4^{\prime \prime}\right.$-hydroxyphenoxy) phenylene] isophthalamide (IPCD), with preformed flexible ether groups and kinked aromatic amide structures. IPCD was utilised to obtain novel, thermally stable, soluble and solution-processable aromatic polyesters and copolyesters. The thermal and structural characterisation of these polyesters is reported.

\section{Experimental}

\subsection{Materials}

All the chemicals were acquired from different companies and utilised exactly as they were provided. Hydroquinone (Loba make, Mumbai, India), p-Chloronitrobenzene, (Spectrochem, Bombay, India), N, N-dimethylformamide, terephthalloyl dichloride (TPC), and isophthalloyl dichloride (IPC) were purified by standard procedures [25]. Potassium carbonate (s d fine) was dried at $100{ }^{\circ} \mathrm{C}$ for $5 \mathrm{~h}$ and stored in a desiccator until use. Methylene dichloride and absolute ethanol were used as received.

\section{Measurements}

Synthesised new bisphenol and intermediate organic compounds and polyesters were scanned for FT-IR spectra on a Nicolet 520 FT-IR spectrometer (Thermo Fisher Scientific, Milan, Italy) using $\mathrm{KBr}$ pellets. ${ }^{1} \mathrm{H}$ NMR $(400 \mathrm{MHz})$ and ${ }^{13} \mathrm{C}$ NMR $(100 \mathrm{MHz})$ spectra were recorded on a Bruker Advance spectrometer (Bruker, Bremen, Germany) at $25^{\circ} \mathrm{C}$ using $\mathrm{CDCl}_{3}$ and $\mathrm{DMSO}-\mathrm{d}_{6}$ as solvents and tetramethylsilane as a reference. Mass spectrum was recorded on the Bruker LCMS/MS (QTOF) instrument (Bruker, Bremen, Germany) using an electrospray ionisation (ESI) technique. Solubility of polyesters was determined by dissolving $10 \mathrm{mg}$ polyester in $1 \mathrm{~mL}$ solvent at room temperature for $24 \mathrm{~h}$. Inherent viscosities of aromatic polyesters were measured with a polyester concentration of $0.5 \mathrm{~g} / \mathrm{dL}$ in N-methyl-2-pyrrrolidone (NMP) solvent at $30^{\circ} \mathrm{C}$ using an Ubbelhode suspended-level viscometer. Differential scanning calorimetry (DSC) was performed on a Mettler Toledo DSC STAR instrument (Mettler Toledo DSC STAR, Zurich, Switzerland) at heating rate of $20{ }^{\circ} \mathrm{C} / \mathrm{min}$. under nitrogen. Thermogravimetric analysis (TGA) was recorded on a Mettler Toledo STAR instrument (Mettler Toledo DSC STAR, Zurich, Switzerland) at a heating rate of $10^{\circ} \mathrm{C} / \mathrm{min}$. under nitrogen on 2-3 mg polyester fibrous samples, which were brought into finely powdered form. Wide-angle X-ray diffraction (WAXD) was recorded with a 
Rigaku X-ray diffractometer with $\mathrm{CuK} \alpha$ radiation (with a wavelength $=1.5418 \AA$ ) on an angular range of $2 \theta=05$ to $60^{\circ}$ with $1.0^{\circ} / \mathrm{min}$. scan increment at room temperature using polyester powder.

\subsection{Synthesis of Bisphenol: $N, N^{\prime}-\left[4^{\prime}-\left(4^{\prime \prime}-H y d r o x y p h e n o x y\right)\right.$ phenylene]isophthalamide}

(a) Synthesis of $4\left(4^{\prime}\right.$-nitrophenoxy)phenol (NPP):

In a $500 \mathrm{~mL}$ one-neck, round bottom flask, hydroquinone $(0.164 \mathrm{~mol}, 18.04 \mathrm{~g})$, pchloronitrobenzene $(0.1148 \mathrm{~mol}, 18.08 \mathrm{~g})$, potassium carbonate $(0.164 \mathrm{~mol}, 22.63 \mathrm{~g})$, and $\mathrm{N}$, $\mathrm{N}$ dimethylformamide $(150 \mathrm{~mL})$ were stirred overnight at $30^{\circ} \mathrm{C}$ and then heated at $100{ }^{\circ} \mathrm{C}$ for $5 \mathrm{~h}$. Afterwards, cooling contents were mixed with cold, 5\% aq. hydrochloric acid to precipitate product. The product was separated by filtration, washed with water, and dried. The product was ethanol-extracted, and the extracts were concentrated. When almost all solvent was removed, the residue was dried under vacuum. Recrystallisation of the residue from aq. ethanol produced a dark yellow pure product (NPP). Yield: $13.19 \mathrm{~g}(49.7 \%)$ and M.P.167- $169^{\circ} \mathrm{C}$.

(b) Synthesis of 4-(4' aminophenoxy)phenol (APP):

In a $250 \mathrm{~mL}$ three-neck, round-bottom flask NPP $(0.044 \mathrm{~mol}, 10.164 \mathrm{~g}), 10 \% \mathrm{Pd} / \mathrm{C}$ $(0.4 \mathrm{~g})$ and $150 \mathrm{~mL}$ ethanol were stirred at $80{ }^{\circ} \mathrm{C}$. Over a period of $1 \mathrm{~h}$, hydrazine hydrate $(99 \%, 20 \mathrm{~mL})$ was added drop-wise to the reaction mixture. Refluxing was continued for $4 \mathrm{~h}$. The reaction mixture was filtered to remove the Pd/C. Distillation of the filtrate was performed to recover about $125 \mathrm{~mL}$ of ethanol. About $150 \mathrm{~mL}$ of water was added to the residue in the reaction flask. Precipitate was collected by filter-funnel, washed with water, and dried. Recrystallisation of product from boiling water gave pure APP. Yield: $6.3 \mathrm{~g}$ (71.3\%) and M.P. $152-153{ }^{\circ} \mathrm{C}$.

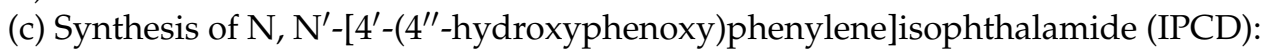

In a $100 \mathrm{~mL}$ three-neck, round-bottom flask, APP (0.402 g, $2 \mathrm{mmol})$ was dissolved in DMAc $(4.4 \mathrm{~mL})$ under nitrogen atmosphere and the solution was cooled to $-15^{\circ} \mathrm{C}$. To the solution of IPC $(0.203 \mathrm{~g}, 1 \mathrm{mmol})$ four lots was added. Stirring was continued for $2 \mathrm{~h}$ at $0{ }^{\circ} \mathrm{C}$ and then for $12 \mathrm{~h}$ at $30^{\circ} \mathrm{C}$. The product was precipitated by mixing water $(60 \mathrm{~mL})$ with the reaction solution. Precipitate was filtered, washed with methanol, and dried (Scheme 1): yield $0.806 \mathrm{~g}(94.9 \%)$; M.P. $290{ }^{\circ} \mathrm{C}$. Mass: $m / z 533(\mathrm{M}+1)$ ion peak.

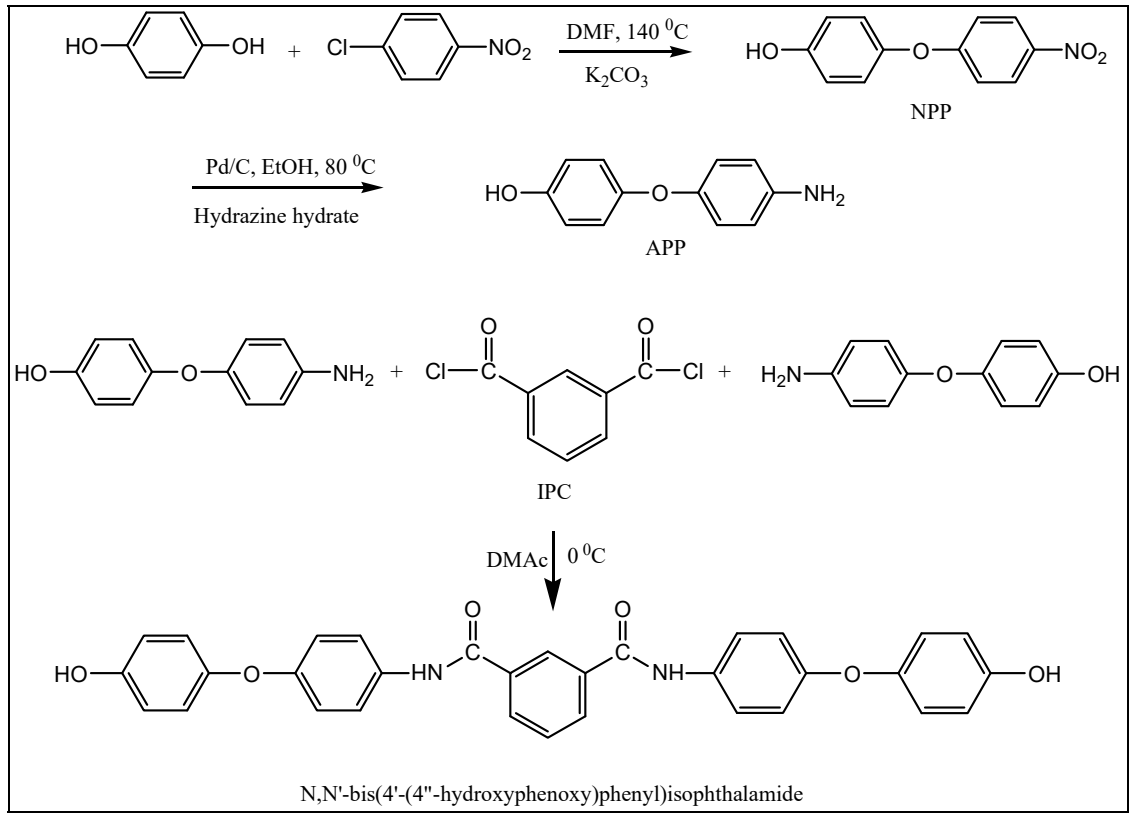

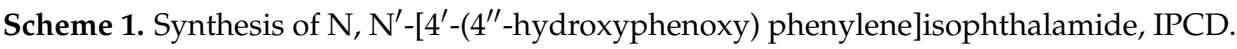




\subsection{Polymerisation}

Scheme 2 illustrates interfacial method of polymerisation for new bisphenol IPCD with aromatic dicarboxylic acid chloride. Procedure adopted to synthesise aromatic polyester was as follows.

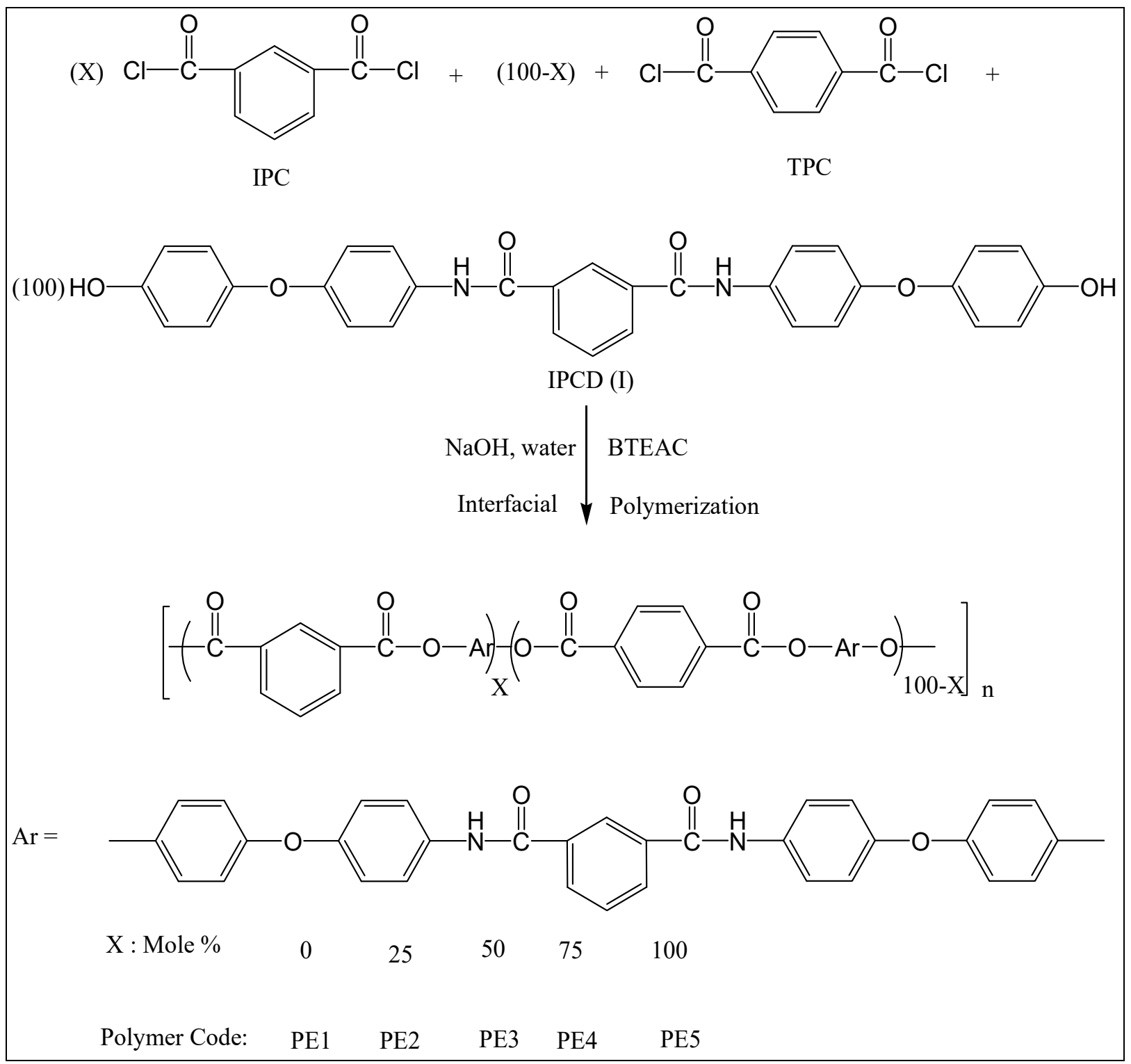

Scheme 2. Synthesis of polyesters.

Synthesis of polyester (PE-5).

A $100 \mathrm{~mL}$ three-neck, round-bottom flask was charged with IPCD $0.532 \mathrm{~g}(1 \mathrm{mmol})$, $\mathrm{NaOH} 0.080 \mathrm{~g}(2 \mathrm{mmol})$, benzyl triethyl ammonium chloride $0.100 \mathrm{~g}$, and water $12.5 \mathrm{~mL}$ and stirred at $0{ }^{\circ} \mathrm{C}$. IPC $0.203 \mathrm{~g}(1 \mathrm{mmol})$ in $8 \mathrm{~mL} \mathrm{DCM}$ was introduced into the flask in one lot. Then, the reaction mixture was stirred vigorously for an hour at $30^{\circ} \mathrm{C}$. The viscous solution was poured into excess hexane to precipitate the polyester, PE-5. The polyester was filtered, washed with distilled water, and dried. Yield: $98 \%$, inherent viscosity, $0.67 \mathrm{dL} / \mathrm{g}$.

Other polyesters PE- 1 to PE-4 were synthesised by similar procedure.

\section{Result and Discussion}

The aim was to prepare modified, soluble, and thermally stable aromatic polyesters and study their thermal as well as structural characterisation. 


\subsection{Bisphenol, $N, N^{\prime}-\left[4^{\prime}-\left(4^{\prime \prime}-H y d r o x y p h e n o x y\right)\right.$ phenylene $]$ isophthalamide Synthesis}

The bisphenol IPCD was synthesised in three steps, including hydroquinone on reaction with p-chloronitrobenzene gave $4\left(4^{\prime}\right.$-nitrophenoxy)phenol (NPP) which, on reduction, gave $4\left(4^{\prime}\right.$-aminophenoxy)phenol (APP). This APP ( $\left.2 \mathrm{~mol}\right)$ on reaction with IPC $(1 \mathrm{~mol})$ gave the desired bisphenol IPCD in, overall, about 34\% yields for three steps.

IPCD was analysed by FT-IR, ${ }^{1} \mathrm{H}$ and ${ }^{13} \mathrm{C}$ NMR spectroscopy, and mass spectrometry. The FT-IR spectrum of IPCD showed a broad absorption band at $3284(\mathrm{O}-\mathrm{H}), 1694(\mathrm{C}=\mathrm{O})$ stretching, 3132, and $3047 \mathrm{~cm}^{-1}(-\mathrm{N}-\mathrm{H})$. The ${ }^{1} \mathrm{H}$ NMR spectrum of IPCD showed a singlet at 10.65 corresponding to the phenolic proton and an 8.77 singlet due to amide $(-\mathrm{NH})$, whereas aromatic protons appeared from 8.33 to $7.15 \delta$ (Figure 1).

IPCD
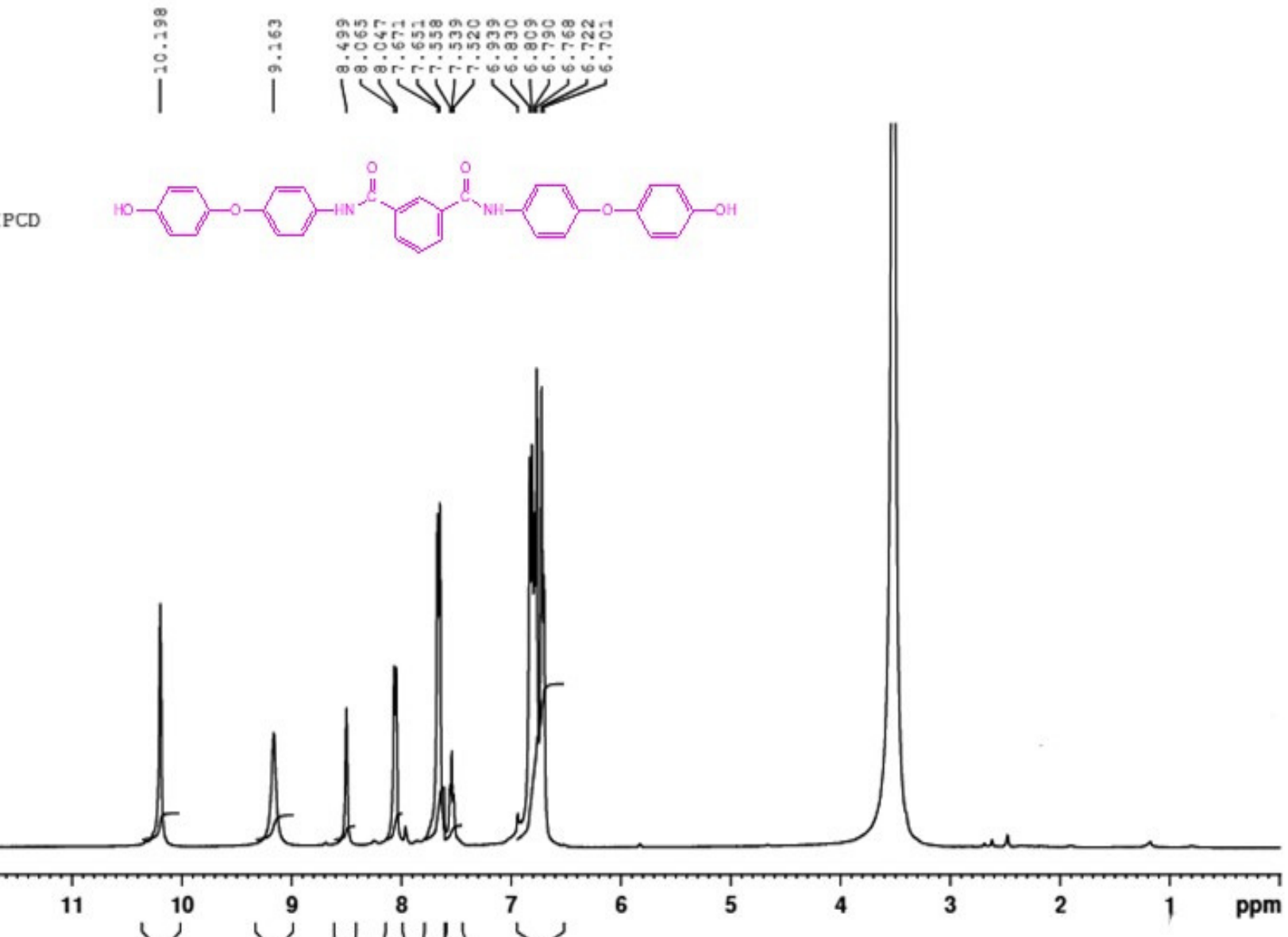

$\delta(\mathrm{ppm})$.

Figure 1. ${ }^{1} \mathrm{H}$ NMR spectrum of IPCD.

Figure 2 shows a ${ }^{13} \mathrm{C}$ NMR spectrum of IPCD. It exhibited 13 different peaks for 13 different non-equivalent carbons. An amide carbonyl peak appeared at 166, and aromatic carbon peaks were in the range of 116 to $154 \delta$. A ${ }^{13} \mathrm{C}$ DEPT NMR spectrum of IPCD confirmed the structure, wherein quaternary carbons were absent (Figure 3). Mass spectrometry of IPCD exhibited a peak at $m / z=533$ units due to the $(\mathrm{M}+1)^{+}$peak, confirming the formation of IPCD as per the assigned chemical structure. 


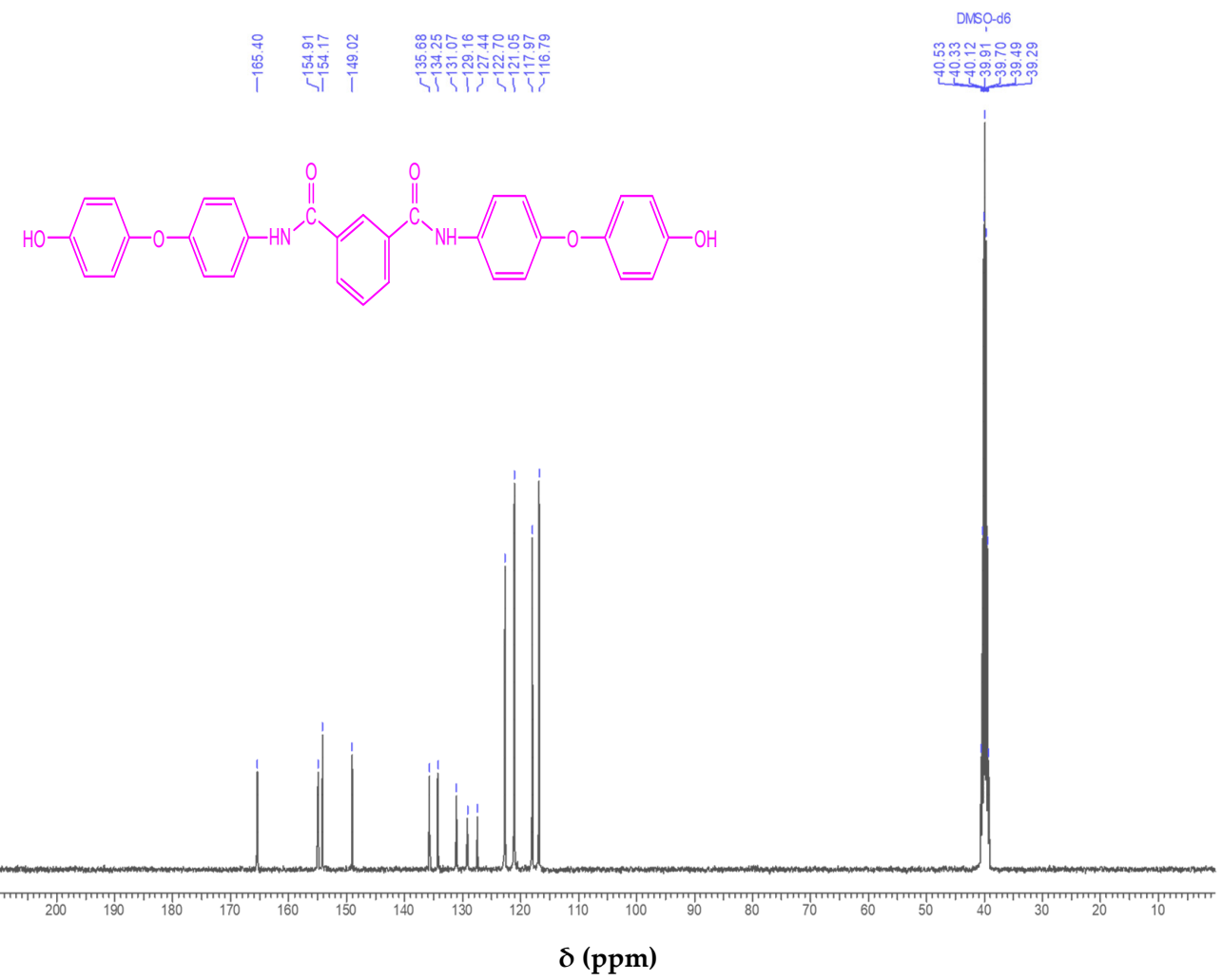

Figure $2 .{ }^{13} \mathrm{C}$ NMR spectrum of IPCD.

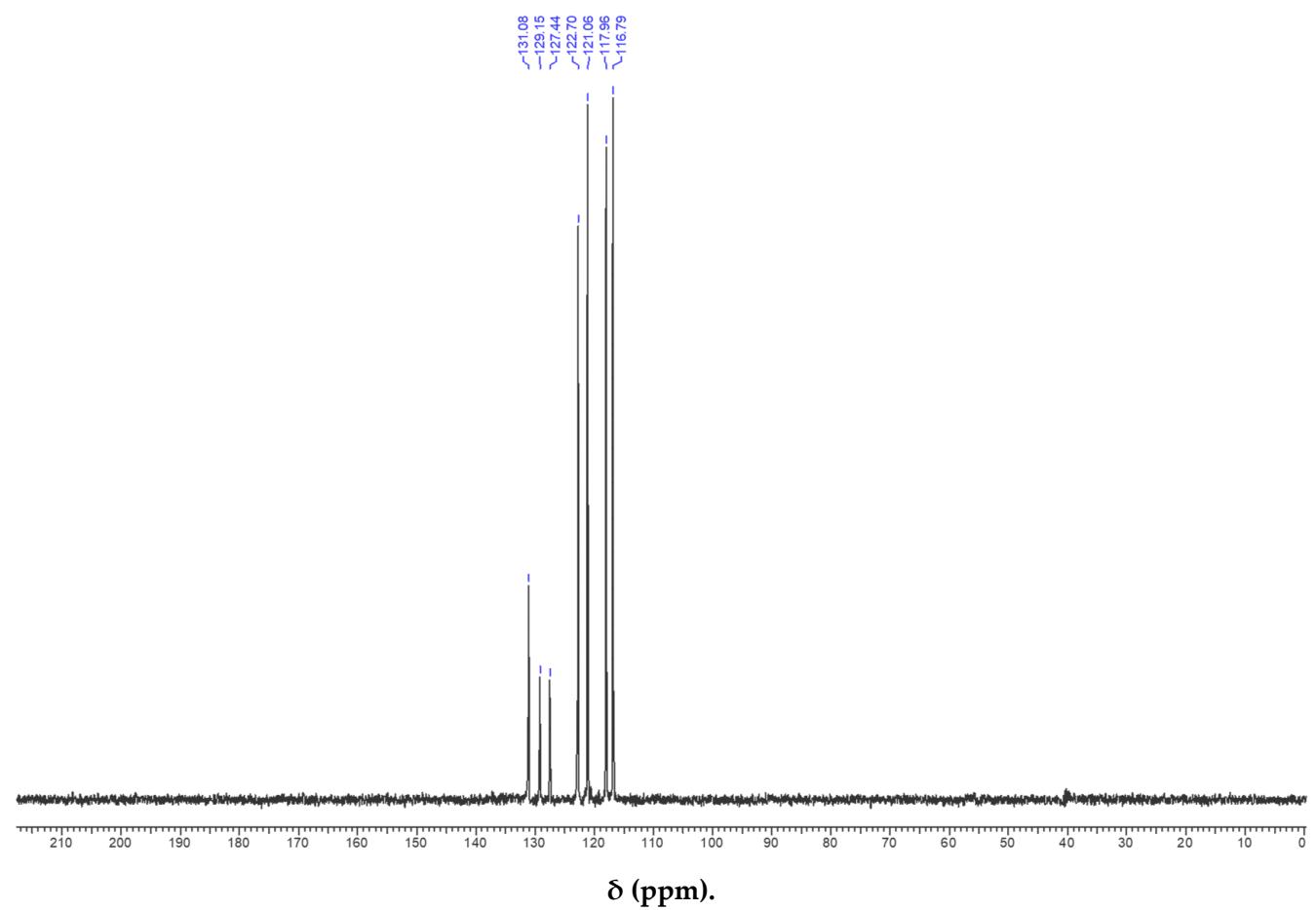

Figure 3. DEPT ${ }^{13} \mathrm{C}$ NMR spectrum of IPCD.

\subsection{Polymerisation}

A series of aromatic polyesters (PE-1 to PE-5) was prepared by utilising an interfacial polymerisation method wherein bisphenol IPCD was reacted with aromatic dicarboxylic acid chloride. The polymerisation was performed at ambient temperature for an hour. The 
polymerisation proceeded smoothly, giving a viscous solution. Polyester was precipitated by pouring the reaction solution into a large volume of hexane.

The inherent viscosities and the yields of these polyesters from IPCD and diacid chlorides are given in Table 1.

Table 1. Inherent viscosities and percentage yields of polyesters ${ }^{\text {a. }}$ (PE-1 to PE-5) from IPCD.

\begin{tabular}{|c|c|c|c|c|c|}
\hline \multirow{2}{*}{ Sr. No. } & \multirow{2}{*}{$\begin{array}{c}\text { Polyester } \\
\text { Code }\end{array}$} & \multicolumn{2}{|c|}{$\mathrm{mol} \%$} & \multirow{2}{*}{ Yield (\%) } & \multirow{2}{*}{$\begin{array}{l}\eta_{\text {inh }} b \\
(d L / g)\end{array}$} \\
\hline & & TPC & IPC & & \\
\hline 1 & PE-1 & 100 & 00 & 96 & 0.78 \\
\hline 2 & PE-2 & 75 & 25 & 97 & 0.75 \\
\hline 3 & PE-3 & 50 & 50 & 97 & 0.73 \\
\hline 4 & PE-4 & 25 & 75 & 96 & 0.69 \\
\hline 5 & PE-5 & 00 & 100 & 98 & 0.67 \\
\hline
\end{tabular}

a Polymerisation was performed using $1 \mathrm{mmol}$ each of IPCD and acidchloride. ${ }^{\mathrm{b}}$ Measured at $0.5 \%$ polyester concentration at $30^{\circ} \mathrm{C}$.

\subsection{Characterisation of Polyesters}

High molecular weight polyesters were obtained as indicated by their inherent viscosities ranging from 0.67 to $0.78 \mathrm{dL} / \mathrm{g}$ in NMP Polyester PE-1 derived from TPC, which showed the highest inherent viscosity among all five polyesters studied, probably due to the higher reactivity of terephthalic acid chloride.

Analysis of polyesters by FT-IR spectroscopy confirmed the formation of the desired polyesters. The FT-IR spectrum of polyester PE-5 is given in Figure 4. The characteristic absorption bands at $1740 \mathrm{~cm}^{-1}$ corresponding to newly formed ester carbonyl $(\mathrm{C}=\mathrm{O}$ stretching) of the polyester, and absorption bands of the preformed amide group at $3267 \mathrm{~cm}^{-1}$ (due to the $-\mathrm{NH}$ stretching) and at around $1672 \mathrm{~cm}^{-1}$ (due to the carbonyl stretching of amide), were seen in the FT-IR spectrum [3,8]. The absence of an absorption band at $3491 \mathrm{~cm}^{-1}$ indicated that all hydroxyl groups of bisphenol reacted completely to yield polyester.

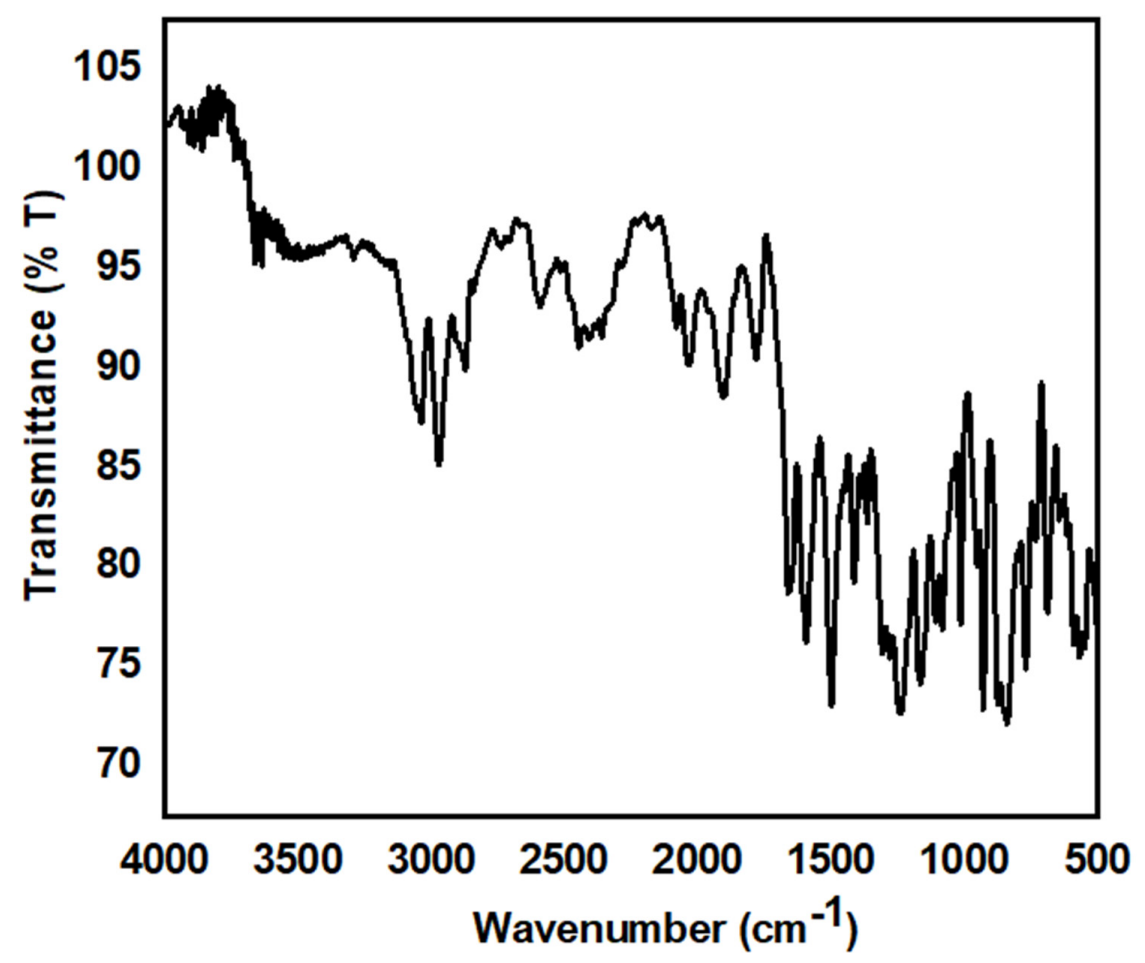

Figure 4. FT-IR spectrum of PE-5. 
Solubility of Polyesters:

Synthesised aromatic polyesters containing multiple ether and amide groups were tested qualitatively for their solubility in various solvents. Polyesters were considered as 'soluble' when tested by dissolving $10 \mathrm{mg}$ of the polyester in $10 \mathrm{~mL}$ of the solvent to give a $1 \%$ polymer solution at $30^{\circ} \mathrm{C}$. All these aromatic polyesters were soluble in polar aprotic solvents and in pyridine.

The aromatic polyesters showed good solubility. This may be due to the incorporation of multiple ether groups. This modification decreased intermolecular interactions between polyester chains, decreased the packing efficiency, and produced the amorphous soluble polyesters. Further m-catenation in the kinked aromatic amide structure in these polyesters favoured better solubility than if it were a p-catenated aromatic amide structure.

All these polyesters (PE-1 to PE-5) were soluble in organic solvents, irrespective of the structure of the diacidchlorides, which indicated that solubility was mainly due to the multiple ether moieties and the kinked 1, 3-phenylene amide structure. These soluble polyesters may find varieties of applications as high-performance polymers in the electronics, automotive, textile, and aerospace industries as films, membranes, coatings, varnishes, adhesives, paints, spun fibres, etc.

Thermal properties of polyesters:

Polyesters were evaluated for the thermal properties by DSC (Figure 5) and TGA (Figure 6) analyses. The glass transition temperature $\left(\mathrm{T}_{\mathrm{g}}\right)$ and initial decomposition temperature $\left(\mathrm{T}_{\mathrm{i}}\right)$, the temperatures of the maximum rate of decomposition $\left(\mathrm{T}_{\max }\right)$, and char yields at $900{ }^{\circ} \mathrm{C}$ of (PE-1 to PE-5) are presented in Table 2. Peaks corresponding to melting were not observed in the DSC curves, indicating that polyesters are amorphous. Polyesters PE-1 to PE-5 showed different $\mathrm{T}_{\mathrm{g}} \mathrm{s}$ from $194^{\circ} \mathrm{C}$ to $269^{\circ} \mathrm{C}$ depending on the structure and stiffness of the diacidchlorides, which decided the rigidity of these polyesters. It was observed that the $\mathrm{T}_{\mathrm{g}}$ value for PE-5, which was derived from m-catenated IPC, was lower $\left(194^{\circ} \mathrm{C}\right)$ than the $\mathrm{T}_{\mathrm{g}}$ values for the remaining four polyesters, PE-1 to PE-4. Aromatic polyester PE-1, which was derived from $\mathrm{p}$-catenated TPC, showed the highest $\mathrm{T}_{\mathrm{g}}\left(269^{\circ} \mathrm{C}\right)$ due to the 1,4 aromatic linkages. The $\mathrm{T}_{\mathrm{g}}$ values of polyesters increased stepwise as the TPC content in the polyesters increased from PE-5 to PE-1, as rigidity increased in diacidchlorides component.

Table 2. Thermal analysis of polyesters (PE-1 to PE-5).

\begin{tabular}{cccccc}
\hline Sr. No. & Polyester Code & $\begin{array}{c}\mathbf{T}_{\mathbf{i}} \\
\left({ }^{\circ} \mathbf{C}\right)\end{array}$ & $\begin{array}{c}\mathbf{T}_{\max } \\
\left({ }^{\circ} \mathbf{C}\right)\end{array}$ & $\begin{array}{c}\text { Residual wt. at } \\
\mathbf{9 0 0}{ }^{\circ} \mathbf{C}(\mathbf{\%})\end{array}$ & $\begin{array}{c}\mathbf{T}_{\mathbf{g}} \\
\left({ }^{\circ} \mathbf{C}\right)\end{array}$ \\
\hline 1 & PE-1 & 325 & 542 & 48 & 269 \\
\hline 2 & PE-2 & 320 & 530 & 45 & 223 \\
\hline 3 & PE-3 & 315 & 525 & 44 & 208 \\
\hline 4 & PE-4 & 309 & 521 & 42 & 198 \\
\hline 5 & PE-5 & 301 & 503 & 39 & 194 \\
\hline
\end{tabular}

Flexible ether moieties in the main chain favoured polyester chain movements, and the $\mathrm{m}$-catenated aromatic amide structure in the main chain broke the linearity of the aromaticity. The combined effect of these two modified units in the polyesters resulted in the lowering of the glass transition temperatures. On the other hand, amide groups in the polyester chains may promote slightly increased $\mathrm{T}_{\mathrm{g}}$ values. Thus, there is an overall effect of the ether as well as amide units. However, the $\mathrm{T}_{\mathrm{g}}$ values of these aromatic polyesters were not as high as those of the wholly aromatic polyester, Ekonol, poly(p-benzoate) $\left(\mathrm{T}_{\mathrm{g}}>500^{\circ} \mathrm{C}\right)$. 


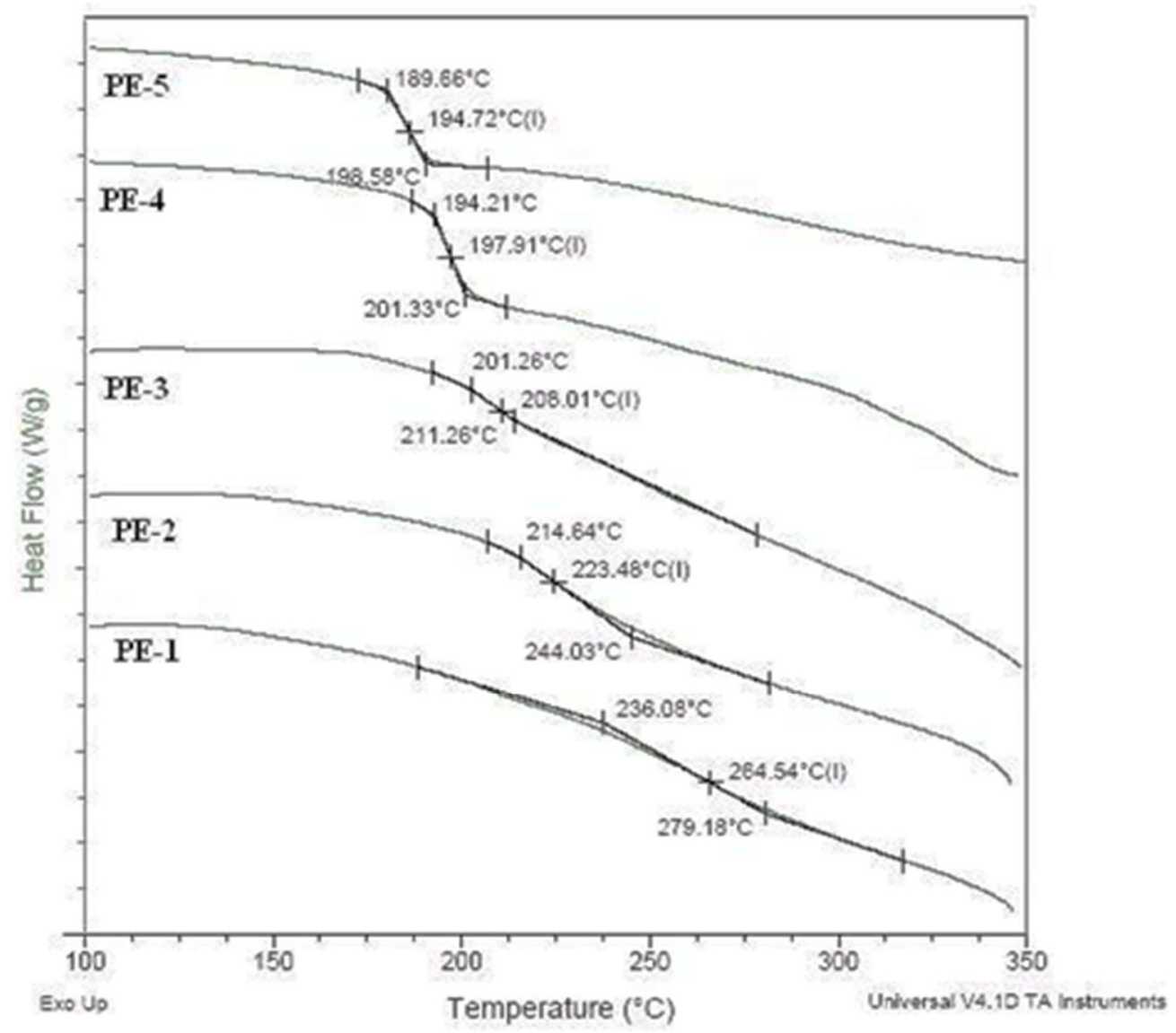

Figure 5. DSC curves of PE-1 to PE-5.

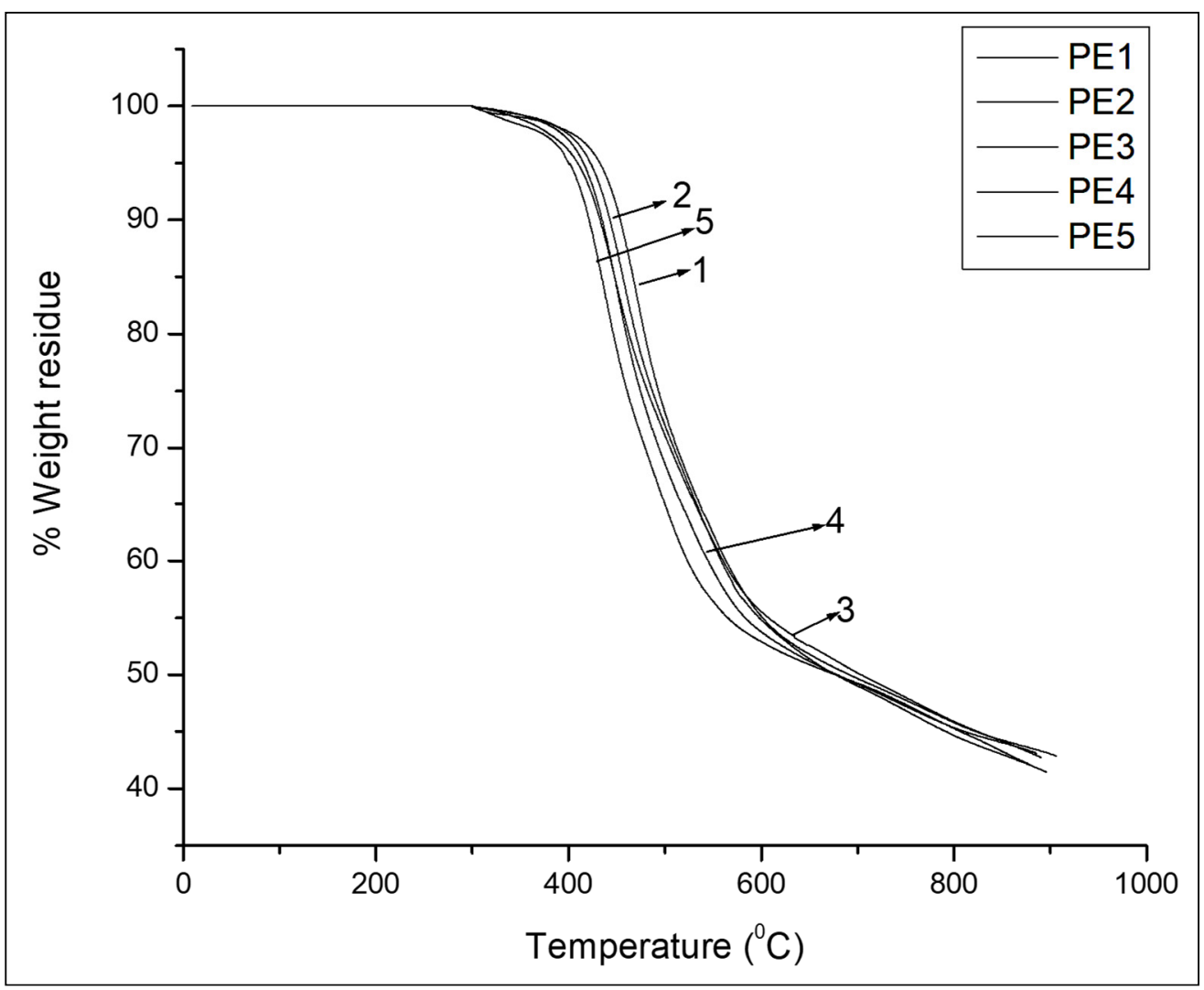

Figure 6. TGA curves of PE-1 to PE-5. 
Aromatic polyesters PE-1 to PA-5 showed no weight loss below 301 to $325^{\circ} \mathrm{C}$, and the $\mathrm{T}_{\max }$ for these aromatic polyesters was from 503 to $542{ }^{\circ} \mathrm{C}$. The residual weights (\%) at $900{ }^{\circ} \mathrm{C}$ for these aromatic polyesters were from $39 \%$ to $48 \%$. All these thermal parameters indicated that the polyesters were highly thermally stable. Large amounts of the aromatic structures and thermally stable amide and ether moieties in the main chain of these polyesters may be prime contributing factors towards good thermal stability.

$X$-ray Diffraction:

XRD of these aromatic polyesters containing multiple ether and amide links was performed for $2 \theta=5-60^{\circ}$ at ambient temperature. Figure 7 shows broad hallow peaks with a slight shoulder at $2 \theta=10-35^{\circ}$ and halos were centred at about $22^{\circ}$, with a minor shoulder holo at about $15^{\circ}$. Polyesters were amorphous, as the XRD diagram did not show any very sharp peaks. The kinked 1, 3-phenylene amide structure and abundant, flexible ether linkages in the main polyester chain may be responsible for producing the amorphous polyesters. Obviously, the improved solubility of these polyesters can be assigned to the completely amorphous nature of these aromatic polyesters and copolyesters.

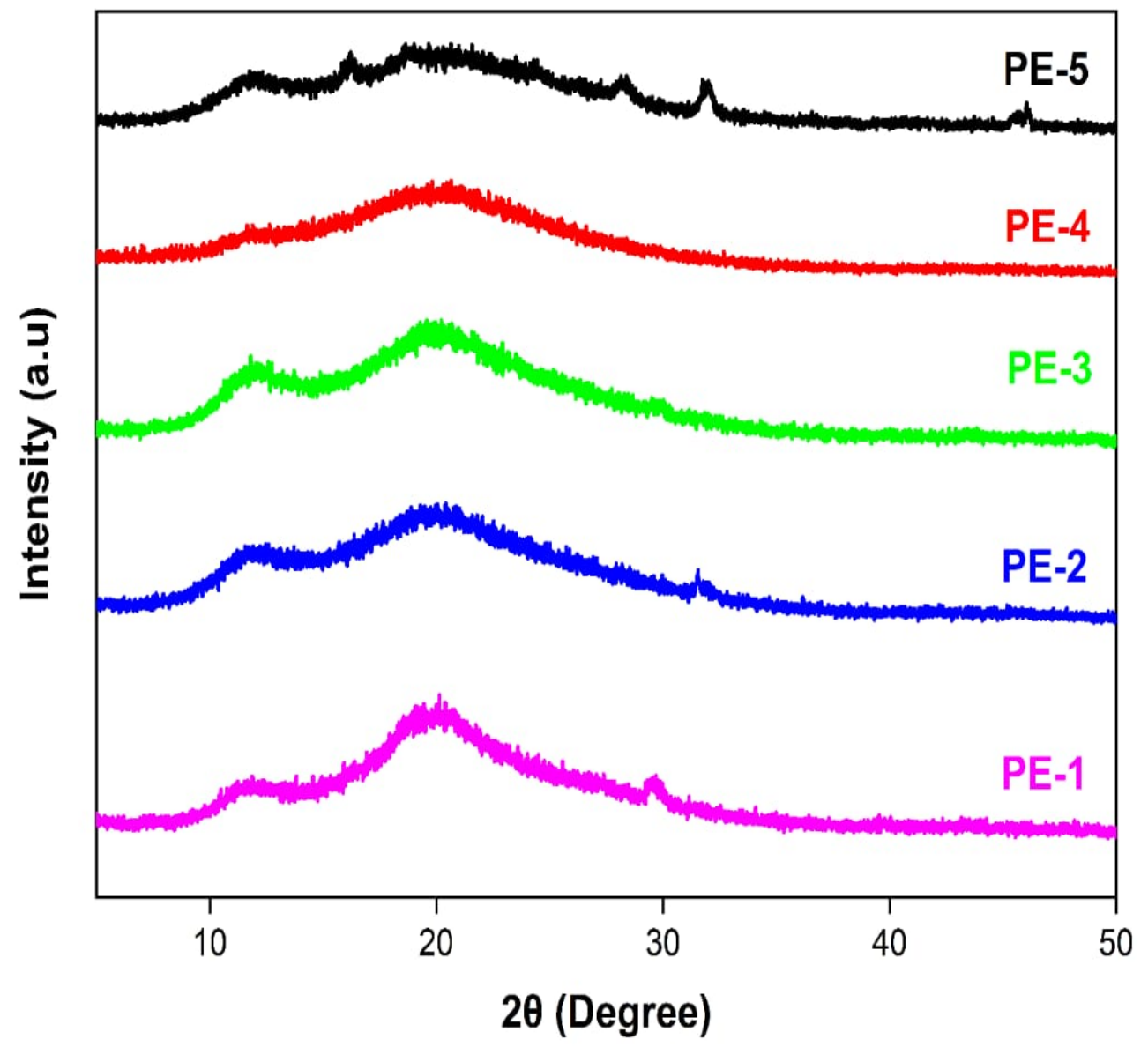

Figure 7. XRD curves of PE-1 to PE-5.

\subsection{Conclusions}

The synthesis of new bisphenol containing two ether moieties and kinked aromatic

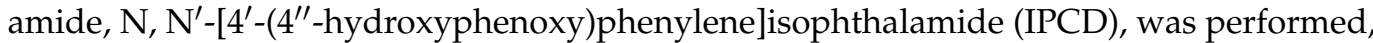
and the bisphenol was completely analysed by spectroscopic methods. Thermally stable and soluble aromatic polyesters containing ether groups and kinked 1, 3-phenylene amide structure were designed and synthesised by an interfacial method from IPCD with two isomeric aromatic dicarboxyllic acid chlorides. The molecular weights of the synthesised polyesters were high, as illustrated through the range of inherent viscosities from 0.67 to $0.78 \mathrm{dL} / \mathrm{g}$ in NMP. Incorporation of the ether groups and kinked 1, 3-phenylene amide 
structure in the main polyester chains resulted in soluble polyesters. Polyesters were dissolved in organic aprotic polar solvents and pyridine. Thus, the obtained soluble aromatic polyesters had good thermal stability and successfully overcame the solution processability issues of wholly aromatic polyesters. These polyesters, when characterised for thermal properties, showed glass transition temperatures from 194 to $269{ }^{\circ} \mathrm{C}$. There was a clear increasing trend in the values of $\mathrm{T}_{\mathrm{g}}$ as the content of TPC increased. Thermogravimetric analysis of these thermally stable aromatic polyesters showed no weight loss below $301{ }^{\circ} \mathrm{C}$, whereas the $\mathrm{T}_{\max }$ was more than $503{ }^{\circ} \mathrm{C}$ and char yields at $900{ }^{\circ} \mathrm{C}$ were from $39 \%$ to $48 \%$. All these prepared polyesters, when studied by WXRD, showed an amorphous nature because the introduction of multiple ethers and a kinked 1, 3-phenylene amide structure may have disrupted the polymer chain packing. These thermally stable, soluble aromatic polyesters could be solution-processable. Thus, studies showed that introducing an ether and $\mathrm{m}$-catenated phenylene structure may be useful to tailor-make $\mathrm{T}_{\mathrm{g}}$ of aromatic high-performance polyesters.

Author Contributions: Writing-original draft, conceptualisation, methodology, and data interpretation, S.S.D.; data curation, validation, and resources, M.D.J.; writing-review and editing, A.M.T.; funding acquisition, S.A. and M.M.G.; visualisation and formal analysis, N.T.N.T.; writing-review and editing, M.S.T.; supervision and project administration, N.N.M. All authors have read and agreed to the published version of the manuscript.

Funding: This research received no external funding.

Institutional Review Board Statement: Not applicable.

Informed Consent Statement: Not applicable.

Data Availability Statement: Not applicable.

Conflicts of Interest: The authors declare no conflict of interest.

\section{References}

1. Imai, Y.; Maldar, N.N.; Kakimoto, M. Synthesis and characterization of soluble aromatic polyazomethines from 2,5-bis(4aminophenyl)-3,4-diphenylthiophene and aromatic dialdehydes. J. Polym. Sci. Polym. Chem. 1984, 22, 3771-3778. [CrossRef]

2. Joshi, M.D.; Lonikar, S.V.; Maldar, N.N.; Wadgaonkar, P.P. Synthesis and Characterization of Phenylated Poly (Phenylquinoxaline)s. J. Macromol. Sci. Part A 1997, 34, 1077-1083. [CrossRef]

3. Honkhambe, P.N.; Avadhani, C.V.; Wadgaonkar, P.P.; Salunkhe, M.M. Synthesis and characterization of new aromatic polyesters containing biphenyl side groups. J. Appl. Polym. Sci. 2007, 106, 3105-3110. [CrossRef]

4. Jadhav, A.S.; Maldar, N.N.; Shinde, B.M.; Vernekar, S.P. Synthesis and characterization of silicon containing polyamides from aromatic sulfone ether diamines and aromatic organosilicon diacid chlorides. J. Polym. Sci. Polym. Chem. 1991, 29, 147-153. [CrossRef]

5. Jadhav, A.S.; Vernekar, S.P.; Maldar, N.N. Synthesis and characterization of new aromatic sulfone ether polyamides containing pendant pentadecyl groups. Polym. Int. 1993, 32, 5-11. [CrossRef]

6. Vibhute, S.S.; Joshi, M.D.; Wadgaonkar, P.P.; Patil, A.S.; Maldar, N.N. Synthesis and characterization of new cardo polyesters. J. Polym. Sci. Polym. Chem. 1997, 35, 3227-3234. [CrossRef]

7. Shigte, R.D.; Chatterjee, D.; Tawade, B.V.; Shrimant, B.; Wadgaonkar, P.P. Aromatic polyesters containing cardo perhydrocumyl cyclohexylidene groups: Synthesis, Characterization and gas permeation study. J. Macromol. Sci. Part A 2019, 56, 136-145. [CrossRef]

8. $\quad$ Bapat, S.P.; Jadhav, S.A.; Valsange, N.G.; Tawade, B.V.; Honkhambe, P.N.; Chavan, N.N.; Wadgaonkar, P.P. Aromatic polyesters containing pendent 4-(phenylsulfonyl)phenyl groups: Synthesis and characterization. J. Polym. Res. 2017, 24, 57. [CrossRef]

9. Tawade, B.V.; Salunke, J.K.; Sane, P.S.; Wadgaonkar, P.P. Processable aromatic polyesters based on bisphenol derived from cashew nut shell liquid: Synthesis and characterization. J. Polym. Res. 2014, 21, 617. [CrossRef]

10. Honkhambe, P.N.; Biyani, M.V.; Bhairamadgi, N.S.; Wadgaonkar, P.P.; Salunkhe, M.M. Synthesis and Characterization of New Aromatic Polyesters Containing Pendent Naphthyl Units. J. Appl. Polym. Sci. 2010, 117, 2545-2552. [CrossRef]

11. More, A.S.; Naik, P.V.; Kumbhar, K.P.; Wadgaonkar, P.P. Synthesis and characterization of polyesters based on 1,1,1-[bis(4hydroxyphenyl)-4'-pentadecylphenyl]ethane. Polym. Int. 2010, 59, 1408-1414. [CrossRef]

12. Ma, X.; Niu, H.; Cai, W.; Xiao, T.; Wang, C.; Bai, X.; Zhang, Y.; Wang, W. New high-solubility aromatic polyesters with pendent phenothiazine: Synthesis, electrochromic and optoelectronic properties. React. Funct. Polym. 2016, 108, 63-70. [CrossRef]

13. Basutkar, P.H.; Joshi, M.D.; Lonikar, S.V.; Maldar, N.N.; Idage, B.B. Synthesis and characterization of phenylated aromatic poly(amide-amide)s. J. Appl. Polym. Sci. 1998, 68, 1523-1530. [CrossRef] 
14. Ubale, V.P.; Sagar, A.D.; Maldar, N.N.; Birajdar, M.V. Synthesis and characterization of aromatic-aliphatic polyamides. J. Appl. Polym. Sci. 2001, 79, 566-571. [CrossRef]

15. Pal, R.R.; Patil, P.S.; Salunkhe, N.N.; Maldar, N.N.; Wadgaonkar, P.P. Synthesis and characterization of aromatic polyamides containing an s-triazine ring with thiophenoxy linkages. Polym. Int. 2005, 54, 569-575. [CrossRef]

16. Patil, V.B.; Medhi, M.; Bhairamadgi, N.S.; Wadgaonkar, P.P.; Maldar, N.N. Synthesis and characterization of polyesters from 2, 3-bis (4'-hydroxy phenyl) quinoxaline and 2, 3-bis (2'-hydroxynaphthalene-6-yl) quinoxaline. Mater. Sci. Eng. B 2010, 168, 186-192. [CrossRef]

17. Brianna, M.; Upton, B.M.; Andrea, M.; Kasko, A.M. Biomass-Derived Poly(ether-amide)s Incorporating Hydroxycinnamates. Biomacromolecules 2019, 20, 758-766.

18. Latha, G.; Murugavel, S.C. Synthesis and characterization of cardo poly (ether-ester)s containing 1, 1-bis (4-hydroxyphenyl) cyclohexane in the main chain. Polym. Bull. 2016, 73, 3237-3253. [CrossRef]

19. Shibasaki, Y.; Mori, T.; Fujimori, A.; Jikei, M.; Sawada, H.; Oishi, Y. Poly(amide-ether) Thermoplastic Elastomers Based on Monodisperse Aromatic Amide Hard Segments as Shape-Memory and Moisture-Responsive Materials. Macromolecules 2018, 51, 9430-9441. [CrossRef]

20. Iyer, K.A. Chain mobility, secondary relaxation, and oxygen transport in terephthalate copolyesters with rigid and flexible cyclic diols. Polymer 2017, 129, 117-126. [CrossRef]

21. Chi, D.; Liu, F.; Hao, C.; Chen, J.; Na, H.; Zhu, J. Identification of side chain effect as an important factor influencing the secondary relaxation of polyesters containing cyclohexylene ring. J. Mater. Sci. 2018, 53, 6234-6250. [CrossRef]

22. Patil, P.S.; Pal, R.R.; Salunkhe, M.M.; Maldar, N.N.; Wadgaonkar, P.P. Synthesis of aromatic poly (amide-imide) s from novel diimide-diacid (DIDA) containing sulphone and bulky pendant groups by direct polycondensation with various diamines. Eur. Polym. J. 2007, 43, 5047-5054. [CrossRef]

23. Pal, R.R.; Patil, P.S.; Salunkhe, M.M.; Maldar, N.N.; Wadgaonkar, P.P. Synthesis, characterization and constitutional isomerism study of new aromatic polyamides containing pendant groups based on asymmetrically substituted meta-phenylene diamines. Eur. Polym. J. 2009, 45, 953-959. [CrossRef]

24. Wu, Z.F.; Zhang, G.; Yan, G.M.; Lu, J.H.; Yang, J. Aromatic polyesters containing different content of thioether and methyl units: Facile synthesis \& properties. J. Polym. Res. 2018, 25, 170-181.

25. Perrin, D.D.; Armarego WL, F.; Perrin, D.R. Purification of Laboratory Chemicals; Pergamon Press: Oxford, UK, 1980. 